\title{
Examining the Factor Structure of the Survey of Attitudes Towards Statistics among Undergraduate Health Science Students
}

\author{
Abraham Ayebo ${ }^{1 *}$, Jered Bright ${ }^{1}$, Christian Ballam ${ }^{1}$ \\ ${ }^{1}$ University of Minnesota Rochester, USA \\ *CORRESPONDENCE: $₫$ aayebo@r.umn.edu
}

\begin{abstract}
Recent studies report that students' attitudes toward statistics play an important role in their statistics achievement. The goal of this study was to test the psychometric properties of the Survey of Attitudes Towards Statistics (SATS-28) among undergraduate health science students enrolled in an introductory statistics course. Most students held positive attitudes towards statistics. The average SATS scores were above neutral. Confirmatory factor analysis validated the four-factor structure of the questionnaire (Affect, Cognitive Competence, Value, and Difficulty), albeit with a few modifications. The RMSEA value of 0.065 was below the suggested cutoff of 0.07 . Cronbach's alpha for the entire scale was .907 , which was well above the recommended cutoff value of 0.7 . The study provided evidence for the appropriate metric properties of the SATS-28 as a valid instrument for measuring the statistics attitudes of a sample of first year students at the University of Minnesota Rochester.
\end{abstract}

Keywords: student attitudes, statistics education, introductory statistics

\section{INTRODUCTION}

The discipline of statistics offers other disciplines a clear and concise set of ideas and tools for analyzing real-life data. The primary goal of most statistics courses is to equip students with basic statistical skills in order for them to appreciate the value of statistics in their professional and personal lives (Reid \& Petocz, 2002; van Appel \& Durandt, 2018). A basic understanding of statistical concepts prepares students to understand previous and current research, generate some of their own research, evaluate practices and draw informed conclusions regarding studies that were undertaken. At the undergraduate level, this could mean being able to evaluate empirical evidence in published material.

However, for most students, statistics is seen only as a professional tool rather than a central skill and their statistics education as part of their degree does not set out to prepare them as statistics practitioners. Rather, it helps them to recognize when they would need the help of a statistician (Reid \& Petocz, 2002). Consequently, statistics represents a new way of thinking for most students and is also seen as a somewhat unexpected component of their studies and future professions (Petocz \& Reid, 2005). Most students find the completion of statistics courses as part of their education quite intimidating (Perepiczka, Chandler, \& Becerra, 2011).

The perceptions and attitudes of students regarding statistics might therefore pose some challenges for everyone teaching statistics. Investigating students' attitudes towards statistics might aid statistics teachers

Article History: Received 1 August $2019 \bullet$ Revised 16 September $2019 \bullet$ Accepted 22 September 2019

(C) 2020 by the authors; licensee Modestum Ltd., UK. Open Access terms of the Creative Commons Attribution 4.0 International License (http://creativecommons.org/licenses/by/4.0/) apply. The license permits unrestricted use, distribution, and reproduction in any medium, on the condition that users give exact credit to the original author(s) and the source, provide a link to the Creative Commons license, and indicate if they made any changes. 
to better prepare and guide students through their statistics education. It can also equip teachers to influence students' perceptions of the role of statistics in their future careers.

Students' level of preparedness to take courses in statistics can be viewed, not only in terms of their mathematical ability but also in terms of affective and attitudinal factors (Finney \& Schraw, 2003; Mulhern \& Wylie, 2004; Perepiczka, Chandler, \& Becerra, 2011). Students often view statistics as one of the biggest hurdles they face in their undergraduate programs. Research has shown that students' attitudes toward statistics courses include anxiety, cynicism, fear and contempt (Berk \& Nanda, 1998; Carnell, 2008; Cushin \& Elmore, 2005; Hopkins, Hopkins \& Glass, 1996). Onwuegbuzie (2004) found that as many as $80 \%$ of students experience anxiety over learning statistics. Students' attitudes toward statistics may create a major obstacle for effective learning (Mills, 2004; Onwuegbuzie \& Seaman, 1995) and as a result, teaching statistics can pose a major instructional challenge to the teacher. In a review of several studies regarding how students learn statistics, Garfield and Ben-Zvi (2007) proposed that teachers need to cultivate more optimistic beliefs about the importance of statistics and statistical literacy. Teachers should also be aware that students come to statistics courses with a range of views concerning their own skill or lack thereof to be successful in the course (Garfield \& Ben-Zvi, 2007). Schau (2003) found that students' attitude toward statistics were positively related to their achievement in statistics. Hilton, Schau and Olsen (2004) noted that there is growing signal to back the belief that students' attitudes toward statistics affects their course enrolment, persistence and achievement in the course. Since students' attitudes toward statistics are critical to their achievement, we must be able to measure them.

Attitude is a multifaceted construct that consists of, cognitive and behavioral components (Perepiczka \& Becerra, 1995; Schau, Stevens, Dauphinee, \& Del Vecchio, 1995). Schau et al. (1995) developed an instrument, the Survey of Attitude Toward Statistics (SATS-28 item version), designed to measure attitudes toward statistics based on four components: affect (positive and negative feelings concerning statistics), cognitive competence (students' attitudes about their own intellectual knowledge and skills when applied to statistics), value (attitudes about the usefulness, relevance and worth of statistics in one's personal and professional life) and difficulty (attitudes about the difficulty of statistics as a subject). The SATS-28 item version has been shown to be valid and reliable in various studies and under various settings (Coetzee \& Merwe, 2010; Mills, 2004; Schau et al. 1995). The 28-item version was extended to a 36 -item version to include two additional components: interest and effort (Schau 2003).

Previous research have shown that attitudes toward statistics are related to prior math experience (Brown \& Brown, 1995; Onwuegbuzie, 2000; Schau, 2003), level of statistics course (Waters et al., 1989), prior statistics experience and GPA (Mills, 2004). Mills (2004) further reviewed scholarship on the influence of gender on statistics attitude and found that the results were mixed. He found that males were less likely than females to report being scared of statistics and not feeling confident mastering statistical material (Mills, 2004). Tempelaar, Gijselaers and Van der Loeff (2006) reported that males scored higher on positive affect toward statistics, cognitive competence related to statistics and difficulty of the subject, but scored lower than females on general interest in the subject and the degree of effort they were planning to put into the study of statistics. They did not find any gender differences about the value of statistics for their individual and professional lives. Age was found to be an influencing factor (Onwuegbuzie, DaRos \& Ryan, 1997; Onwuegbuzie, 2000).

The aim of this paper is to determine the validity and reliability of the SATS-28 item version as an instrument to measure attitude toward statistics in a sample of undergraduate health science students.

\section{METHOD}

\section{Participants}

The participants were 119 undergraduate health science students enrolled in a first year statistics course at the University of Minnesota Rochester. The majority of the sample were females (76\%) and mostly Caucasian (93\%). The average age was 18.25 and the ages ranged from 17 to 27.

The University of Minnesota Rochester is the newest branch within the University of Minnesota system. At University of Minnesota Rochester, faculty and staff seek to inspire innovations in higher education through commitment to teaching excellence and the scholarship of teaching and learning. The educational approach is highly individualized and technology-enhanced. 
The course of interest for this study, Math 1161 Introduction to Statistics, is a course that is typically taken by first year students in their fall semester of study. The course typically begins with a broad overview of the entire course, then proceeds to investigate data and data representations while utilizing Microsoft Excel followed by the basics of experimental design, fundamental probability properties including conditional probability and the Normal distribution, theoretical frameworks for statistical inference including the Central Limit Theorem and Law of Large Numbers, and finally concludes with quantitative statistical inference methods.

In delivering the course, the instructional team (which includes experienced faculty and undergraduate academic assistants who had excellent performance in the course the previous year) is highly aware of the student population needs and seeks to support the students in the course as they transition to university life. During class, students are seated in groups and experience cycles of direct instruction and active learning. While engaged in active learning, students work on exercises with nearby group members while members of the instructional team circulate to answer questions and provide feedback to students. Outside of class, students do have homework and studying to complete and frequently visit faculty to get questions answered.

\section{Instrument}

The Survey of Attitude Toward Statistics, SATS-28 (Schau, 1995) was used to measure students' attitudes toward statistics. The SATS-28 uses a 7-point Likert scale $(1=$ strongly disagree, $4=$ neither disagree nor agree, $7=$ strongly agree) which consist of four subscales: Affect, Cognitive Competence, Value and Difficulty. Affect measures what students feel about statistics (e.g. 'I get frustrated going over statistics tests in class'). It comprises six items with internal reliability measures between 0.80 and 0.89 . Cognitive competence investigates students' attitudes about their intellectual knowledge and skills when applied to statistics (e.g. 'I understand statistics equations'). It has six items with Cronbach's alpha values ranging from 0.77 to 0.88. Value measures students' perception of how useful statistics is in their personal and professional life (e.g. 'Statistical thinking is not applicable in my life outside my job'). It is measured by nine items with reliability coefficients ranging between 0.74 and 0.90 . Difficulty is a measure of students' perception of the difficulty of statistics as a subject (e.g. 'Statistics is a complicated subject'). It is made up of seven items and has reliability coefficients ranging between 0.64 and 0.81. Schau et al. (1995) confirmed the four-factor structure of the 28item version through confirmatory factor analysis. The estimated correlations among the four factors of the 28-item version were significant, except for the correlation between value and difficulty (Schau et al., 1995).

\section{Statistical Analysis}

Confirmatory factor analysis was used to determine the validity of the SATS-28 for the population of undergraduate health science students at the University of Minnesota Rochester. The confirmatory factor analysis was performed using IBM SPSS AMOS version 23 (Arbuckle, 2015). Following Brown (2014) and Kline (2013), the following fit indices were reported: The model chi-square $\left(\mathrm{X}^{2}\right)$, Steiger-Lind root mean square error of approximation (RMSEA) with the 90\% confidence interval, the Bentler comparative fit index (CFI), the standardized root mean square residual (SRMR), and the normed chi-square value $\left(\mathrm{x}^{2} / d f\right)$.

The model chi-square is an inferential statistic that tests the null hypothesis that the model fits the analyzed covariance matrix. A significant value $(p<.05)$ indicates poor fit. Although the chi-square is an important statistic for understanding model fit, it is sensitive to large sample size and may result in a poor indication of model fit (Kline, 2013). This sensitivity is minimized by using the normed chi-square. A value of 3 or less can be used as an indicator of model fit when the model chi-square is significant. Following Steiger (2007) as well as $\mathrm{Hu}$ and Bentler (1999), additional criteria for model fit were set as follows: RMSEA <.07, $\mathrm{SRMR}<.08, \mathrm{CFI}>.9, \mathrm{GFI}>.9$ and $\mathrm{SRMR}<.08$.

A series of confirmatory factor analyses were performed to obtain the best model fit. Maximum likelihood estimation procedures were used. The models were over-identified (number of observed variables $>$ number of parameters) and all variables were scaled. A covariance matrix (not presented in the paper) was used to estimate the model. Cronbach alpha coefficients were determined to indicate the reliability of the sub-factors of the survey.

\section{RESULTS}

The SATS-28 questionnaire was administered to 119 first year undergraduate health science students enrolled in an introductory statistics course at the University of Minnesota Rochester. The mean age of the 
Table 1. Fit indices for the SATS-28 models

\begin{tabular}{lccccc}
\hline Model & $\mathrm{X}^{\mathbf{2}}(\boldsymbol{d} \boldsymbol{f})$ & $\mathrm{X}^{\mathbf{2}} / \boldsymbol{d} \boldsymbol{f}$ & RMSEA (90\% CI) & SRMR & CFI \\
\hline Four-factor (Baseline) & $611.97(344) p \leq .05$ & 1.78 & $.078(.068-.088)$ & .083 & .82 \\
\hline Modified 4-factor & $528.13(341) p \leq .05$ & 1.55 & $.065(.054-.076)$ & .079 & .88 \\
\hline Three-factor & $619.86(347) p \leq .05$ & 1.79 & $.078(.068-.088)$ & .084 & .82 \\
\hline Modified 3-factor & $532.30(344) p \leq .05$ & 1.55 & $.068(.054-.076)$ & .079 & .87 \\
\hline
\end{tabular}

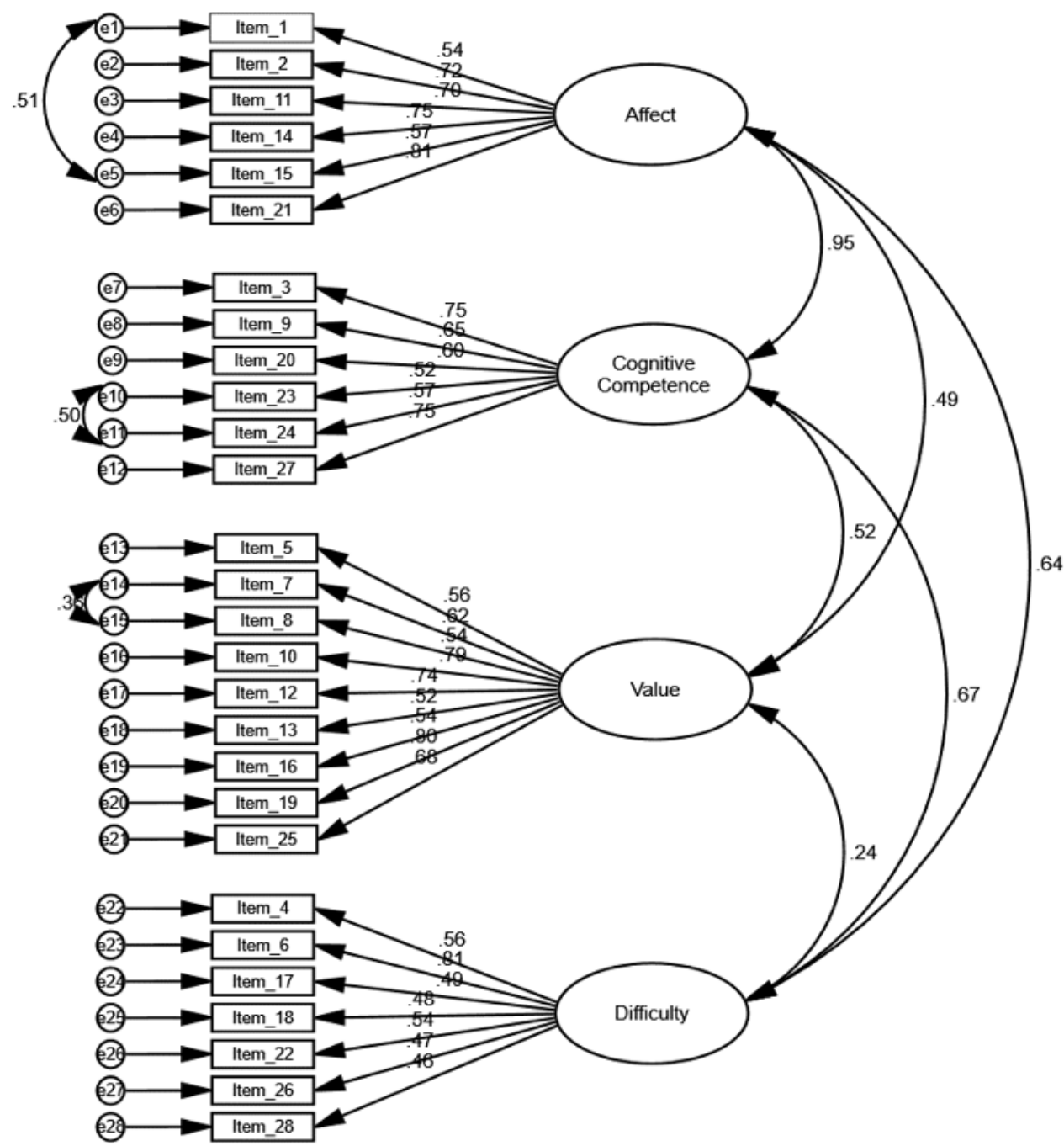

Figure 1. Revised 4-factor model of the SATS-28 showing standardized parameter estimates

students was 18.25 (range: 17-27 years) and most participants were female (76\%) and Caucasian (93\%). Most of the participants held positive attitudes towards statistics.

Using the IBM SPSS AMOS Version 23 software, we performed a series of confirmatory factor analyses to obtain the best model fit for our sample. A summary of the fit indices is presented in Table 1. The baseline model (4-factor structure) resulted in a $\mathrm{X}^{2}(344, N=119)=611.97, p \leq .05$. The fit indices were not acceptable (Kline, 2010). The model yielded an RMSEA $=0.078$, SRMR $=.083, \mathrm{CFI}=.82$, and normed chi-square $=1.78$. Using the modification indices, we then modified the baseline model by letting the errors of items 1 and 15 correlate. Item 1 "I will like statistics" and item 15 "I will enjoy taking statistics courses" are both used as indicators of the Affect component. Conceptually, it makes sense to correlate these items since they measure the same construct. We also correlated the error terms of items 7("Statistics should be a required part of my professional training") and 8 ("Statistical skills will make me more employable") and items 23("I can learn statistics") and 24("I understand statistics equations"). Again, both pair of error terms measure the same construct; items 7 and 8 measure Value, and items 23 and 24 measure Cognitive Competence, and both pairs are somewhat similarly worded, so there is conceptual justification for correlating them. The path diagram for the revised 4-factor model is shown in Figure 1. 
Table 2. Cronbach's Alpha values for each component of the SATS instrument

\begin{tabular}{cc}
\hline Construct & Cronbach's Alpha \\
\hline Affect & .873 \\
\hline Cognitive Competence & .866 \\
\hline Value & .903 \\
\hline Difficulty & .716 \\
\hline Overall & .907 \\
\hline
\end{tabular}

Table 3. Mean scores and standard deviations for the subscales of the SATS $28(\mathrm{~N}=119)$

\begin{tabular}{ccc}
\hline Construct & M & SD \\
\hline Affect & 4.44 & 1.42 \\
\hline Cognitive Competence & 5.02 & 1.28 \\
\hline Value & 5.15 & 1.28 \\
\hline Difficulty & 3.58 & 1.15 \\
\hline Total & 4.58 & 1.27 \\
\hline
\end{tabular}

The revised 4-factor model resulted in a $\mathrm{X}^{2}(341, N=119)=528.13, p<.05$. The fit indices were as follows: RMSEA $=0.065, \mathrm{SRMR}=.079, \mathrm{CFI}=.88$, and normed chi-square $=1.55$. These results are obviously a big improvement over the baseline model. The Chi-square statistic, while still not significant, has dropped from 611.97 to 524.13 . The difference Chi-square test is $\Delta X^{2}(3)=7.82$. The RMESA and the SRMR values are both below the recommended cutoff values of .07 and .08 respectively. While the CFI value is still below the .9 threshold, it is quite close and a noticeable improvement over that of the baseline model.

The next model we considered was a 3-factor model where Affect and Cognitive Competence were combined. This model resulted in a $\mathrm{X}^{2}(347, N=119)=619.86, p<.05$. The fit indices were as follows: RMSEA $=0.078$, $\mathrm{SRMR}=.084, \mathrm{CFI}=.82$, and normed chi-square $=1.79$. The fit indices clearly suggest an unacceptable model fit. Finally, we applied modification indices to the 3-factor model by correlating the error terms of items 1 and 15, 23 and 24, and 7, and 8. The modified 3-factor model resulted in a $\mathrm{X}^{2}(344, N=119)=532.30, p<.05$. The fit indices were as follows: $\mathrm{RMSEA}=0.068, \mathrm{SRMR}=.079, \mathrm{CFI}=.87$, and normed chi-square $=1.55$.

\section{DISCUSSION}

This study sought to investigate the psychometric properties of Schau's (1995) SATS-28 instrument among a sample of undergraduate health science students enrolled in introductory statistics at the University of Minnesota Rochester. Means and standard deviations of the SATS-28 components, shown in Table 3, were comparable to previous studies (Cashin, 2005; Chiesi \& Primi, 2009; Schau, 1995). The SATS-28 components' means were neutral or above, implying positive student attitudes towards statistics. The overall findings of the study provide evidence for the validity and reliability of the SATS-28 item for the sample of undergraduate health science students. Confirmatory factor analysis validated the modified version of the four-factor structure of the questionnaire where error terms of items 1 and 15, 23 and 24, and 7 and 8 were allowed to correlate. Based on the pre-established fit indices thresholds, only the modified four-factor model can be considered acceptable. The four factors were significantly correlated, with the strongest correlation emerging between Affect and Cognitive Competence (.95). This is consistent with findings from previous studies (Chiesi \& Primi, 2009; Persson, Kraus, Hansson, \& Wallentin, 2019; Tremblay, Gardner, \& Heipel, 2000; Zhang et al., 2012). The SATS-28 showed good internal consistency, the Cronbach's alpha was 0.907 for the overall scale, similar to other versions (Schau, 1995). Internal consistency coefficients for Affect, Cognitive Competence, Value, and Difficulty were $.873, .866, .903$, and .716 respectively. This finding is consistent with those obtained in other validation studies. Schau (1995) reported that Cronbach's alpha values ranged from 0.80 to 0.89 for Affect, from 0.77 to 0.90 for Cognitive Competence, from 0.74 to 0.91 for Value, and from 0.64 to 0.86 for Difficulty.

\section{Limitations of the Study}

As stated earlier, a convenience sample of undergraduate students enrolled in a health science program was recruited for this study; thus, due to the nature of the population, there was a disproportionate number of females and Caucasian students in the sample. Therefore the sample was not as diverse as one would expect. Also, the analysis was based on self-reported data which can promote bias. Therefore, this study cannot be generalized to other samples with different demographics. 


\section{CONCLUSION}

The present study provided evidence for the appropriate metric properties of the SATS-28. Confirmatory factor analysis validated the four-factor structure of the scale. Good indices for both validity and reliability were obtained. The results confirmed the psychometric characteristics of the questionnaire observed in other student populations. The overall finding is that SATS-28 might be a reliable and a valid instrument for identifying undergraduate health science student attitudes towards statistics.

\section{Recommendations}

Future studies should expand the investigations into statistics attitude predictor variables that includes previous statistics experience and other factors to predict students' course grades in the statistics course. Also, future research should include much broader demographics of undergraduate students that represent various races, ethnicities, age groups, etc. Finally, future studies should address classroom and counselling based intervention to help reduce students' statistics anxiety.

\section{ACKNOWLEDGEMENTS}

The authors would like to thank Candace Schau for granting permission to use the SATS-28 Survey instrument.

\section{Disclosure statement}

No potential conflict of interest was reported by the authors.

\section{Notes on contributors}

Abraham Ayebo - University of Minnesota Rochester, USA.

Jered Bright - University of Minnesota Rochester, USA.

Christian Ballam - University of Minnesota Rochester, USA.

\section{REFERENCES}

Arbuckle, J. L. (2015). IBM SPSS Amos user's guide [Computer software and manual].

Berk, R. A., \& Nanda, J. P, (1998). Effects of jocular instructional methods on attitudes, anxiety, and achievement in statistics courses. International Journal of Humor Research, 11, 383-409. https://doi.org/10.1515/humr.1998.11.4.383

Brown, T. A. (2014). Confirmatory factor analysis for applied research. NY, USA: Guilford Publications. https://doi.org/10.1080/00036811.2013.839780

Brown, T. S., \& Brown, J. T. (1995). Prerequisite course grades and attitude toward statistics. College Student Journal, 29, 502-507.

Carnell, L. J. (2008). The effect of a student-designed data collection project on attitudes towards Statistics. Journal of Statistics Education, 16(1). https://doi.org/10.1080/10691898.2008.11889551

Chiesi, F., \& Primi, C. (2009). Assessing statistics attitudes among college students: Psychometric properties of the Italian version of the Survey of Attitudes toward Statistics (SATS). Learning and Individual Differences, 19(2), 309-313. https://doi.org/10.1016/j.lindif.2008.10.008

Coetzee, S., \& Merwe, P. V. D. (2010). Industrial psychology students' attitudes towards statistics. SA Journal of Industrial Psychology, 36(1), 1-8. https://doi.org/10.4102/sajip.v36i1.843

Cushin, S. E., \& Elmore, P. B. (2005). The Survey of Attitudes toward Statistics scale: A construct validity study. Educational and Psychological Measurement, $\quad 65(3), \quad$ 1-16. https://doi.org/10.1177/0013164404272488

Dauphinee, T. L., Schau, C., \& Stevens, J. J. (1997). Survey of Attitudes Toward Statistics: Factor structure and factorial invariance for females and males. Structural Equation Modeling, 4(2), 129-141. https://doi.org/10.1080/10705519709540066

Finney, S. J., \& Schraw, G. (2003). Self-efficacy beliefs in college statistics courses. Contemporary Educational Psychology, 28(2), 161-186. https://doi.org/10.1016/s0361-476x(02)00015-2 
Gal, I., \& Ginsburg, L. (1994). The role of beliefs and attitudes in learning statistics: Toward an assessment framework. Journal of Statistics Education, 2(2). https://doi.org/10.1080/10691898.1994.11910471

Garfield, J., \& Ben-Zvi, D. (2007). How students learn statistics revisited: A current review of research on teaching and learning statistics. International statistical review, 75(3), 372-396. https://doi.org/10.1111/j.1751-5823.2007.00029.x

Hilton, S. C., Schau, C., \& Olsen, J. A. (2004). Survey of Attitudes Toward Statistics: Factor structure invariance by gender and sample sizes. British Journal of Mathematical Statistical Modeling, 11(1), 92-109. https://doi.org/10.1207/S15328007SEM1101_7

Hopkins, K. D., Glass, G. V., \& Hopkins, B. R. (1987). Basic statistics for the behavioral sciences. Prentice-Hall, Inc.

Hu, L. T., \& Bentler, P. M. (1999). Cutoff criteria for fit indexes in covariance structure analysis: Conventional criteria versus new alternatives. Structural equation modeling: a multidisciplinary journal, 6(1), 1-55. https://doi.org/10.1080/10705519909540118

Kline, R. (2013). Exploratory and Confirmatory Factor Analysis. In Applied quantitative analysis in education and the social sciences (pp. 183-217). Routledge.

Mills, J. (2004). Students' attitudes toward statistics: Implications for the future. College Student Journal, 38(3), 349-362.

Mulhern, G., \& Wylie, J. (2004). Changing levels of numeracy and other core mathematical skills among psychology undergraduates between 1992 and 2002. British Journal of Psychology, 95(3), 355-370. https://doi.org/10.1348/0007126041528176

Onwuegbuzie, A. J. (2000). Academic procrastinators and perfectionistic tendencies among graduate students. Journal of Social Behavior and Personality, 15(5), 103.

Onwuegbuzie, A. J. (2004). Academic procrastination and statistics anxiety. Assessment \& Evaluation in Higher Education, 29(1), 3-19. https://doi.org/10.1080/0260293042000160384

Onwuegbuzie, A. J., \& Seaman, M. A. (1995). The effect of time constraints and statistics test anxiety on test performance in a statistics course. The Journal of experimental education, 63(2), 115-124. https://doi.org/10.1080/00220973.1995.9943816

Onwuegbuzie, A. J., Da Ros, D., \& Ryan, J. M. (1997). The Components of Statistics Anxiety: A Phenomenological Study. Focus on Learning Problems in mathematics, 19(4), 11-35.

Perepiczka, M., Chandler, N., \& Becerra, M. (2011). Relationship between graduate students' statistics selfefficacy, statistics anxiety, attitude toward statistics, and social support. https://doi.org/10.15241/mpa.1.2.99

Persson, I., Kraus, K. Hansson, L. \& Wallentin, F. Y. (2019). Confirming the structure of the Survey of Attitudes toward Statistics (SATS-36) by Swedish Students. Statistics Education Research Journal, 18(1), 83-93.

Petocz, P., \& Reid, A. (2005). Something strange and useless: Service students' conceptions of statistics, learning statistics and using statistics in their future profession. International Journal of Mathematical Education in Science and Technology, 36(7), 789-800. https://doi.org/10.1080/00207390500271503

Reid, R.A., \& Petocz, P. (2002). Students' conceptions of statistics: A phenomenographic study. Journal of Statistics Education, 10(2). https://doi.org/10.1080/10691898.2002.11910662

Roberts, D. M., \& Bilderback, E. W. (1980). Reliability and validity of a statistics attitude survey. Educational and Psychological Measurement, 40(1), 235-238. https://doi.org/10.1177/001316448004000138

Schau, C. (2003, August). Students' attitudes: The "other" important outcome in statistics education. Paper presented at the Joint Statistical Meetings in San Francisco, CA.

Schau, C., Stevens, J., Dauphinee, T. L., \& Del Vecchio, A. (1995). The development and validation of the Survey of Attitudes toward Statistics. Educational and Psychological Measurement, 55(5), 868-875. https://doi.org/10.1177/0013164495055005022

Tempelaar, D. T., Gijselaers, W. H., van der Loeff, S. S., \& Nijhuis, J. F. (2007). A structural equation model analyzing the relationship of student achievement motivations and personality factors in a range of academic subject-matter areas. Contemporary Educational Psychology, 32(1), 105-131. https://doi.org/10.1016/j.cedpsych.2006.10.004 
Tremblay, P. F., Gardner, R. C., \& Heipel, G. (2000). A model of the relationships among measures of affect, aptitude, and performance in introductory statistics. Canadian Journal of Behavioural Science, 32(1), 40. https://doi.org/10.1037/h0087099

van Appel, V., \& Durandt, R. (2018). Dissimilarities in Attitudes between Students in Service and Mainstream Courses towards Statistics: An Analysis Conducted in a Developing Country. EURASIA Journal of Mathematics, Science and Technology Education, 14, 8. https://doi.org/10.29333/ejmste/91912

Zhang, Y., Shang, L., Wang, R., Zhao, Q., Li, C., Xu, Y., \& Su, H. (2012). Attitudes toward statistics in medical postgraduates: measuring, evaluating and monitoring. BMC Medical Education, 12(1), 117. https://doi.org/10.1186/1472-6920-12-117 